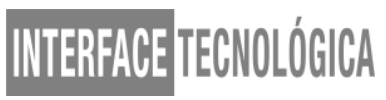

\title{
A SAÚdE E A SEGURANÇA OCUPACIONAL NA GESTÃO DE DOCUMENTOS EMPRESARIAIS
}

\author{
SALUD Y SEGURIDAD OCUPACIONAL EN LA GESTIÓN DE DOCUMENTOS \\ COMERCIALES
}

\author{
João Victor dos Reis - jjoaoreiis@gmail.com \\ Faculdade de Tecnologia (Fatec) - Taquaritinga - SP - Brasil \\ Daniela Rodolpho - daniela.rodolpho@fatec.sp.gov.br \\ Faculdade de Tecnologia (Fatec) - Taquaritinga - SP - Brasil
}

DOI: 10.31510/infa.v17i2.1031

Data de publicação: 18/12/2020

\begin{abstract}
RESUMO
Nos dias de hoje, tudo que é gerado tem seu registro, quando pessoas nascem acontece o registro do seu nascimento, quando uma empresa nasce precisa ser registrada, assim como uma peça é produzida ela também vai ter seu registro de alguma forma. Para se desenvolver este estudo aplicou uma metodologia de revisão literária com base em um pesquisa bibliográfica sobre o tema. Como resultados observa-se que tudo são documentos, arquivos, informações de extrema importância. São produzidas grandes quantidades de informações nas empresas, desde seus documentos até suas atividades rotineiras. Infelizmente a forma de armazenagem nem sempre é organizada e não recebem os devidos cuidados. A gestão do acervo de documentos de uma empresa também pode prejudicar a saúde do profissional que precisa manusear diariamente os documentos em busca de atender as necessidades de informações solicitadas pela empresa que o produziu, ou de usuários que buscam a informação. A terceirização de documentos cuida e trata com procedimentos especializados, organiza e gerencia de forma apropriada e eficaz para o mantimento dos documentos. Concluiu-se que com tudo isso a empresa paga mais barato pela guarda do documento, liberando um enorme espaço no estoque, e o principal sem colocar seus trabalhadores em risco.
\end{abstract}

Palavras-chave: Arquivos. Sistema. Terceirização. Organização.

\begin{abstract}
Nowadays, everything that is generated has its registration, when people are born the registration of their birth happens, when a company is born it needs to be registered, just as a piece is produced it will also have its registration in some way. To develop this study, a literature review methodology was applied based on a bibliographic research on the topic. As a result, it is observed that everything is documents, files, information of extreme importance. Large amounts of information are produced in companies, from their documents to their
\end{abstract}


routine activities. Unfortunately, the form of storage is not always organized and does not receive proper care. The management of a company's document collection can also harm the health of the professional who needs to handle the documents on a daily basis in order to meet the information needs requested by the company that produced it, or of users who seek the information. Document outsourcing takes care of and deals with specialized procedures, organizes and manages appropriately and effectively for the maintenance of documents. It was concluded that with all this, the company pays cheaper to keep the document, freeing up a huge space in the stock, and the main one without putting its workers at risk.

Keywords: Files. System. Outsourcing. Organization.

\section{INTRODUÇÃO}

O custo de um estoque parado pode trazer prejuízos para a empresa. Pode-se considerar o excesso de documentos como um estoque parado, o estoque excessivo significa gastar dinheiro a toa, é assumir custo que não retorna benefício algum. O termo estoque tem um alcance muito amplo. Pode-se considerá-lo como representativo de matérias-primas, produtos semi acabados, componentes para montagem, sobressalentes, produtos acabados, suprimentos variados e o foco neste trabalho será falar no estoque de materiais administrativos.

Os documentos sempre foram essenciais para a as organizações e por motivos legais profissionais ou pessoais, muitos documentos simplesmente não podem ser descartados. Poucos Gestores e Empreendedores dão a devida importância para a Gestão Documental. Porém, guardar documentos, apesar de obrigatório, não é simples. Ainda é possível se encontrar documentos acumulados em depósitos de materiais velhos, banheiros, salas sem usos, entre outros. Com isso, pode acarretar muitos riscos: poeira, fungos, umidade, incêndio, alagamento, entre outros, resultando a perda de informações importantes, e colocando a empresa em situações de riscos na saúde, fiscal e trabalhista. Além de ocupar um grande espaço inadequado e pagar mais caro por esse tipo de armazenamento. Só guardar documentos corretamente não é o suficiente. A qualidade das decisões empresariais depende essencialmente do acesso rápido à informação, ou seja, precisamos encontrá-los quando necessário (MARCELINO; CAVALCANTE, 2012).

Com isso surge uma empresa no mercado, com o foco de guardar e gerenciar os documentos de outras organizações. A empresa terá seu estoque reduzido liberando espaço, e 


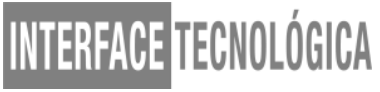

seus documentos terão os cuidados que realmente precisam. Logo quando necessário uma informação/documento, a empresa conseguirá acessá-lo rapidamente e enviar para o solicitante, seja de forma digital (digitalizado), ou forma física.

Contratando a terceirização de documentos a empresa só tem a ganhar. Ganhara liberação de espaço no estoque, pagará mais barato no metro quadrado que ficaram os documentos, terá uma gestão de documentos e não ficar desprovido quando precisar de informações essenciais (MARCELINO; CAVALCANTE, 2012).

Deste modo, o presente estudo objetivou apontar a importância da terceirização na gestão de documentos empresariais. Com isso, utilizou-se de uma pesquisa bibliográfica para a realização da pesquisa em questão.

\section{DESENVOLVIMENTO}

\subsection{A Terceirização na Gestão Documental}

A terceirização na contratação de sistemas de gestão documental para empresas, é um tema atual que põe em causa a forma clássica de gerir os dados com que se trabalham todos os dias. Onde se armazena? Como os procura? O que se faz quando precisa recuperar um determinado documento? Diante dessas questões, os gestores, como responsáveis pela coordenação dos diversos departamentos para a consecução de seus objetivos, devem agir em conformidade.

Não ter um plano de gerenciamento de documentos terá graves consequências para as empresas. Ineficiência, processos lentos, perda de tempo, desorganização e erros em documentos são alguns dos efeitos da má gestão das informações (BALBINO; SILVA, 2016).

É um fato que nos gabinetes em que não se estabelece um plano de gestão documental, acaba sempre o colapso de fichários e estantes cheias de papéis, o que dificulta a sua manutenção e procura (MARCELINO; CAVALCANTE, 2012). No final, todo esse processo tem impacto sobre:

1. Duplicidade. Multiplica-se a possibilidade de haver documentos armazenados duas vezes, o que aumenta o descontrole das informações. 


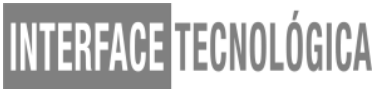

2. Maior gasto de dinheiro. As organizações que não gerenciam suas informações corretamente gastam muito mais papel do que as empresas que o fazem. No final, aumenta o custo do papel, tinta, impressoras, etc.

3. Perda de tempo. Quanto tempo se leva para pesquisar um determinado documento?

4. Dificuldades em partilhar informação com outros departamentos da empresa, com clientes, fornecedores etc., o que se traduz em mau serviço e má imagem da empresa.

O gestor das empresas deve ter uma série de atitudes e habilidades alinhadas com os objetivos da organização. $\mathrm{O}$ aumento da produtividade do funcionário está diretamente relacionado às atribuições desse profissional, e a importância de seu cargo justifica a quantidade de atitudes que ele deve ter (MEDEIROS; AMARAL, 2010). A seguir, mostra-se os motivos pelos quais se tem um sistema de gerenciamento de documentos (MARCELINO; CAVALCANTE, 2012):

1. Aumente a segurança reduzindo as chances de perda de documentos importantes.

2. Maior eficiência por saber a todo o momento o que fazer e onde ir para consultar um determinado documento.

3. Favorece a colaboração entre os funcionários.

4. Ele permite que se faça pesquisas personalizadas e encontre documentos apenas digitando uma ou mais palavras.

5. Aumente o espaço físico disponível no escritório e a organização do mesmo.

6. Maior economia de custos e tempo.

Por tudo isso e muito mais, a gestão de documentos desempenha um papel decisivo que os gestores não devem perder de vista. $\mathrm{O}$ aumento da terceirização de gerenciamento de documentos não é surpreendente, considerando que a maioria das empresas vê sua solução de gerenciamento de documentos como uma parte inconveniente de suas operações funcionais. As empresas estão cientes de que de vez em quando pode causar atrasos desnecessários. Além de atrasos, o gerenciamento de documentos também resulta em um processo ainda mais desorganizado (MARCELINO; CAVALCANTE, 2012).

Esses inconvenientes podem levar a erros e redundâncias que poderiam ser facilmente evitados consultando especialistas experientes em gerenciamento de documentos. Essas pessoas podem fornecer uma solução holística e abordagem para o gerenciamento de conteúdo empresarial, que desempenha um papel fundamental no controle das informações 


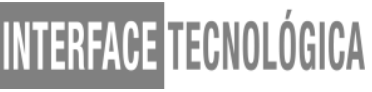

em sua empresa. A eficácia de seu sistema de gerenciamento de documentos pode ter um impacto negativo ou positivo em seus processos de negócios.

Depois de determinar a importância do gerenciamento de documentos, é natural que saibamos mais sobre o que é e como você pode aproveitar ao máximo seus benefícios quando o processo é feito como deve ser (BALBINO; SILVA, 2016).

O gerenciamento de documentos é frequentemente referido como Sistemas de Gerenciamento de Documentos (SGD). Este processo usa software de gerenciamento de documentos para armazenar, gerenciar e rastrear documentos eletrônicos.

O gerenciamento de documentos é um dos avanços precursores no gerenciamento de conteúdo. Mas antes de se tornar popular, o gerenciamento de documentos estava disponível exclusivamente em uma base independente, como irmãos de imagem, fluxo de trabalho e arquivamento. Nos primeiros anos do sistema de gerenciamento de documentos, ele não é considerado tão necessário quanto outras funções. Tudo mudou quando as empresas descobriram os benefícios que o sistema de gerenciamento de documentos oferece, especialmente quando uma empresa de terceirização de boa reputação é contratada para fazer o trabalho (MEDEIROS; AMARAL, 2010).

As empresas de terceirização fornecem algumas das funcionalidades mais básicas para o gerenciamento de conteúdo, como a imposição de controles e recursos de gerenciamento a documentos "estagnados". Além disso, eles agora têm a capacidade de criar software ou programas que podem lidar com procedimentos mais complicados no processo de gerenciamento de documentos. Isso é extremamente conveniente quando se tem uma pilha de documentos e precisa procurar um arquivo específico imediatamente.

\section{METODOLOGIA}

A pesquisa tem por natureza qualitativa, onde foi realizada uma busca em trabalhos e documentos nas bases científicas, onde encontram-se disponíveis os principais periódicos de artigos publicados no Brasil e no mundo.

As bases que foram utilizadas são: o Web of Knowledge, Scielo, Emerald, Spell e Elservier. Os termos utilizados nas bases da pesquisa foram: gestão, documentos, terceirização, empresas. Neste contexto de pesquisa prévia, foi definido o problema do trabalho, que se classifica como exploratória, onde se objetivou proporcionar ao seu final 


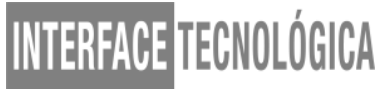

desta pesquisa uma base consolidada a fim de se construir uma estrutura argumentativa que vise atender aos objetivos propostos.

A partir de Gil, (2008), as principais vantagens da pesquisa bibliográfica se consolidam e mostram-se na medida em que possibilitam a explicação de diversos fenômenos das mais diversas formas possíveis, desde a descritiva a mais conceitual possível. Neste trabalho a pesquisa bibliográfica teve cunho de revisão bibliográfica ou de literatura.

\section{RESULTADOS E DISCUSSÃO}

Os sistemas de gerenciamento de documentos possuem diversos benefícios e ferramentas entre si. Estas novidades refletem o crescimento e a importância da gestão documental para as empresas ao longo dos anos se aproxima e as previsões já indicavam que o compromisso das empresas com este tipo de software continuará a aumentar (MARCELINO; CAVALCANTE, 2012).

A terceirização da gestão de documentos é uma estratégia incomparável que permite que as empresas se concentrem em suas necessidades principais de negócios e atendam melhor seus clientes. É também uma forma eficaz de construir uma cultura capaz de se adaptar às mudanças a qualquer momento. Hoje, muitas empresas estão revisando suas operações em profundidade para entender suas verdadeiras competências essenciais e determinar quais processos terceirizar para se tornarem mais eficientes (BALBINO; SILVA, 2016).

A terceirização com um provedor de gerenciamento de documentos para serviços não essenciais, como destruição de documentos, armazenamento e imagens, pode liberar seus processos de negócios de maneira econômica, permitindo que se concentre em seus objetivos de negócios principais. Alguns sinais de que sua empresa deve considerar a terceirização incluem um alto volume de transações, requisitos de processos complexos e / ou crescimento dinâmico. Isso também pode ser ideal se sua empresa estiver sob pressão para reduzir custos.

Qualquer chance de diminuir os custos de processamento de transações libera capital que pode ser aplicado em iniciativas mais estratégicas (OLIVEIRA, 2015).

Um provedor de gerenciamento de documentos oferece às empresas mais tempo para se destacarem e se concentrarem em suas principais iniciativas. As empresas podem economizar dinheiro e reduzir o excesso de pessoal, pois não precisam facilitar e apoiar 


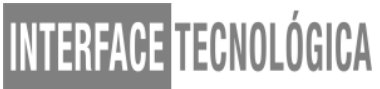

processos como destruição, armazenamento e geração de imagens de documentos diariamente (DA FONSECA, 2020).

O custo do gerenciamento deficiente de documentos está continuamente aumentando e pode custar milhões de dólares à sua empresa. As violações de dados não só custam dinheiro, mas também custam a confiança do público, o que muitas vezes dificulta a recuperação das empresas (MEDEIROS; AMARAL, 2010). O provedor certo fornecerá uma cadeia de custódia ininterrupta durante todo o ciclo de vida de todos os seus documentos. Além disso, irá garantir que sua empresa cumpra as regulamentações governamentais para permanecer em conformidade e com credibilidade.

Ao lidar com as necessidades de gerenciamento de documentos internamente, as empresas tendem a comprar tecnologia de ponta. No entanto, podem surgir problemas se sua empresa tiver um crescimento rápido. Algumas empresas precisam contratar e treinar rapidamente uma equipe adicional e, potencialmente, implantar novo hardware ou software para dar suporte ao crescimento, o que pode ser caro e demorado. Em parceria com um provedor de gerenciamento de documentos seguro, a empresa pode obter acesso instantâneo a recursos de tecnologia de classe mundial que as operações internas tradicionais podem não ter a capacidade financeira de suportar - a um preço econômico (MEDEIROS; AMARAL, 2010).

É fundamental proteger de forma proativa as informações confidenciais de empresas e clientes. Com o roubo de identidade e violações de dados em alta, a parceria com um provedor com certificação e compatível é fundamental. A conformidade certifica que a organização segue os requisitos abrangentes definidos para garantir a integridade dos dados. Uma instalação adequada de armazenamento de documentos está equipada com sistemas de segurança 24 horas, sistemas de alarme e proteção completa contra incêndio para proteger seus documentos em todos os momentos.

Mais distante, um serviço de imagens hospedará arquivos em um ambiente seguro e fornecerá backup completo, redundância e recuperação de desastres para garantir que seus arquivos nunca sejam perdidos ou comprometidos. Por último, todos os documentos que precisam ser destruídos são constantemente monitorados e protegidos até serem destruídos (MARCELINO; CAVALCANTE, 2012).

Cada empresa tem desafios únicos quando se trata de necessidades de gerenciamento de documentos. Seu provedor pode oferecer soluções personalizadas para atender às necessidades de seu negócio. Por exemplo, se sua empresa requer retenção de registro de 


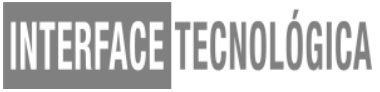

longo prazo, mas tem um baixo volume de recuperação, provavelmente não será viável ou econômico converter todos os arquivos. Uma alternativa viável é fazer parceria com um provedor que pode armazenar e gerenciar grandes volumes de arquivos existentes fora do local, mas entregar registros em papel em formato eletrônico "sob demanda". Isso permite que os funcionários trabalhem com registros eletrônicos diariamente e economiza significativamente para a empresa ao converter anos de registros físicos (MEDEIROS; AMARAL, 2010). Não importa o tamanho de sua organização ou quais processos precisam de suporte, seu provedor pode criar uma solução personalizada para complementar suas necessidades de negócios.

Muitas empresas têm um grupo de funcionários gerenciando e mantendo o fluxo do processo para uma abundância de documentos internos, como arquivos de recursos humanos. Ao usar um provedor de gerenciamento de documentos, a equipe poderá se concentrar nas principais responsabilidades de seu trabalho, em vez de se preocupar com imagens, arquivamentos intermináveis e perda de tempo tentando localizar registros perdidos.

Não se pode desperdiçar espaço valioso de construção para armazenamento de arquivos. Um provedor de armazenamento de documentos é ideal se sua empresa tem um grande volume de registros com taxas de retenção longas, mas espaço limitado. O uso de um provedor de armazenamento seguro não apenas liberará espaço, mas oferecerá uma instalação de armazenamento segura equipada com câmeras de segurança 24 horas, sistemas de alarme e sistemas completos de proteção contra incêndio para proteger os registros de catástrofes, como inundações e incêndios. Seus arquivos serão armazenados com segurança e é uma alternativa eficiente para despesas de gerenciamento interno (MEDEIROS; AMARAL, 2010).

Gerenciar grandes quantidades de dados internamente pode ser difícil de controlar e frequentemente se torna um pesadelo logístico. Usando soluções de imagem e armazenamento, se pode localizar e obter acesso a qualquer arquivo a qualquer momento (SCHELLENBERG, 2006). Por exemplo, com imagens, uma vez que os arquivos são carregados no banco de dados seguro, eles são organizados de acordo com suas especificações, simplificando o processo de recuperação e fornecendo um sistema amigável para filtragem e análise. No ambiente de armazenamento, todos os documentos são rastreados por um sistema de código de barras e podem ser localizados imediatamente. Esse acesso instantâneo elimina as suposições na localização de arquivos e permite que os funcionários se concentrem em suas principais responsabilidades de trabalho (DA FONSECA, 2020). 


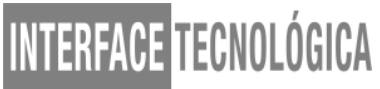

Não importa o setor, a terceirização de serviços ou equipamentos de impressão é provavelmente a estratégia mais eficiente e, portanto, a mais fácil. A impressão fica no final da cadeia de processamento e, portanto, tem apenas uma interface para os processos restantes - é consideravelmente mais barata quando terceirizada. As economias de escala ocorrem principalmente na impressão em cores de alto volume tornando-o ainda mais atraente para empresas que se esquivam dos grandes investimentos necessários.

Considerando-se o arquivamento, ele também pode ser terceirizado, e é mais do que razoável considerando os requisitos crescentes de segurança de revisão. Quanto maior o número de documentos diferentes e complexos e quanto mais regras, mais terceirização faz sentido. Quem quer amarrar legiões de recursos para, por exemplo, uma auditoria financeira potencial, para que todos os dados necessários possam ser preparados imediatamente? Este tópico gera muita controvérsia em todos os setores da indústria (SCHELLENBERG, 2006). Os defensores são altos e claros: o arquivamento pertence à nuvem e, se o servidor estiver dentro da UE, a privacidade dos dados não é um problema. Enquanto isso, muitos provedores de serviços de impressão grande oferecem arquivamento - até porque hoje os limites do negócio de impressão não são tão grandes. Mesmo assim, a tendência aqui é lenta. A maioria das empresas ainda faz seu próprio arquivamento (DA FONSECA, 2020).

A flexibilidade também é uma chave. Com que rapidez os negócios da empresa mudam? Com que frequência os processos mudam e com que frequência são adicionados novos? Com que rapidez a empresa deve responder às novas condições de mercado e reconfigurar os fluxos de trabalho? Como regra geral, quanto mais padronizados os processos e maior o volume de documentos, mais lucrativa é a terceirização. Qualquer empresa que envia correspondências em massa regulares de alto volume faria bem em confiar em um terceiro ou em mídias eletrônicas (MORAIS et al., 2020). Os principais provedores de serviços são conhecidos por gerenciarem grandes quantidades de dados de forma extremamente bem e, devido ao volume, são capazes de fornecer seus serviços a um custo razoável. Escolher o provedor certo é a segunda tarefa mais importante.

É aconselhável trabalhar com consultoria especializada. Fornecedores internacionalmente ativos como a Compart são conhecidos por sua abordagem holística com vista ao processamento geral de documentos (MARQUES, 2020). Qualquer empresa que pretenda terceirizar todo ou parte do processamento de documentos deve primeiro analisar detalhadamente suas estruturas de gerenciamento de saída.

Interface Tecnológica - v. 17 n. 2 (2020) 


\section{CONCLUSÃO}

Finalmente, quanta terceirização as estruturas de gerenciamento de produção da empresa permitirão? Ao contrário dos grandes fornecedores, os menores podem estabelecer novos processos mais rapidamente, como mudar temporariamente para um canal de saída alternativo para apenas alguns documentos.

Se o volume de seus documentos geralmente é baixo e se deseja terceirizar o máximo de processos possível, um provedor menor, mas com uma posição mais ampla, é melhor. No entanto, se os processos são altamente padronizados e sujeitos a poucas mudanças, os fornecedores maiores fazem sentido - especialmente para processamento em massa, como alto volume, impressão transacional em cores (faturas, salários e recibos de pagamento, contas de consumo, extratos de conta, etc.).

Como as grandes empresas são especializadas e extremamente bem equipadas, elas conseguem gerenciar melhor grandes volumes e oferecer melhores preços por seus serviços, especialmente para impressão em cores (economia de escala). O provedor de serviços deve se comunicar sempre com a empresa em nível de pares e oferecer a melhor segurança de dados disponível, certificada se possível de acordo com as diretrizes nacionais e internacionais.

\section{REFERÊNCIAS}

BALBINO, G.M.S; SILVA, W.A. Outsourcing em Arquivos Públicos: Uma Análise Crítica Sobre A Gestão Documental Terceirizada. ÁGORA: ARQUIVOLOGIA EM DEBATE, v. 26, n. 52, p. 91-118, 2016.

DA FONSECA, C.M.G. Gestão Documental e Gestão de Recursos Humanos: Contribuição para o Desenvolvimento do Módulo iPortalDoc-RH. 2020. Disponível em: $<$ https://repositorio-aberto.up.pt/handle/10216/128578>. ACESSO EM: 20 out 2020.

GIL, A.C. Como Elaborar Projetos de Pesquisa. 4. ed. São Paulo: Atlas, 2008.

MARCELINO, P.; CAVALCANTE, S. For A Definition Of Outsourcing. Caderno Crh,Salvador, v. 25, n. 65, p. 331-346, 2012. Disponível em:

$<$ HTTPS://WWW.SCIELO.BR/SCIELO.PHP?SCRIPT=SCI_ARTTEXT\&PID=S0103$49792012000200010>$. Acesso em: 20 out 2020. 
MARQUES, J.A.C. CANEDO MATEUS. Análise da Usabilidade de um Sistema de Gestão Documental em Consultoria Empresarial. 2020. Tese de Doutorado. Disponível em: HTTP://COMUM.RCAAP.PT/HANDLE/10400.26/32391. Acesso em: 20 out 2020.

MEDEIROS, N. L. DE; AMARAL, C. M. G. A Representação do Ciclo Vital dos Documentos: Uma Discussão Sob a Ótica da Gestão de Documentos. Em Questão, Porto Alegre, v. 16, n. 2, p. 297-310, jul./dez. 2010.

MORAIS, S.C.B. et al. Tecnologia da Informação e Desempenho da Gestão Documental em uma Universidade Federal. Perspectivas em Ciência da Informação, v. 25, n. 1, p. 3-30, 2020 .

OLIVEIRA, M. I. A Terceirização dos Serviços na Área de Arquivos: Uma Questão a ser Resolvida. Acervo, Rio De Janeiro, v. 28, n. 2, p 192-205, jul./dez. 2015.

SCHELLENBERG, T. R. ARQUIVOS MODERNOS: PRINCÍPIOS E TÉCNICAS. TRAD. NILZA TEIXEIRA SOARES. 4. ED. RIO DE JANEIRO: FGV, 2006. 